\title{
Pulmonary renal syndrome in a child with coexistence of anti-neutrophil cytoplasmic antibodies and anti-glomerular basement membrane disease: case report and literature review
}

Radovan Bogdanović ${ }^{1,2^{*}}$, Predrag Minić ${ }^{1,2}$, Jasmina Marković-Lipkovski ${ }^{1}$, Nataša Stajić ${ }^{1,2}$, Nataša Savić ${ }^{1,2}$ and Milan Rodić

\begin{abstract}
Background: Pulmonary renal syndrome (PRS), denoting the presence of diffuse alveolar hemorrhage and glomerulonephritis as manifestations of systemic autoimmune disease, is very rare in childhood. The coexistence of circulating anti-neutrophil cytoplasmic antibody (ANCA) and anti-glomerular basement membrane (GBM) disease in children affected by this syndrome is exceptional, with unfavorable outcome in five out of seven patients reported to date. We describe a child with PRS associated with both circulating anti-myeloperoxidase (anti-MPO) ANCA and anti-GBM disease on renal biopsy who was successfully treated with immunosuppressive therapy.
\end{abstract}

Case presentation: A 10-year old girl presented with fever, fatigue, malaise, and pallor followed by hemoptysis and severe anemia. Diffuse alveolar hemorrhage was revealed on fiberoptic bronchoscopy. Renal findings consisted of microscopic hematuria, moderate proteinuria, and anti-GBM disease on renal biopsy. ANCA with anti-MPO specificity were present whereas anti-GBM antibodies were on borderline for positivity. Methyl-prednisolone pulses followed by prednisone led to cessation of hemoptysis, marked improvement of lung fuction, and normal finding on chest $\mathrm{x}$-ray within 10 days. An immunosuppressive regimen was then given consisting of prednisone daily for 4 weeks with subsequent taper on alternate day, i.v. cyclophosphamide pulses monthly for 6 doses, followed by mycophenolate mofetil that resulted in normal lung function tests, hemoglobin concentration, and anti-MPO level within four subsequent weeks. During 10-months of follow-up she remained well, her blood pressure and renal function tests were normal, and proteinuria and hematuria gradually resolved.

Conclusion: We report a child with an exceptionally rare coexistence of circulating ANCA and anti-GBM disease manifesting as PRS in whom renal disease was not the prominent part of clinical presentation, contrary to other reported pediatric patients. A review of literature on disease with double positive antibodies is also presented. Evaluation of a patient with PRS should include testing for presence of different antibodies. An early diagnosis and rapid institution of aggressive immunosuppressive therapy can induce remission and preserve renal function. Renal prognosis depends on the extent of kidney injury at diagnosis and appropriate treatment.

Keywords: Pulmonary renal syndrome, Children, Anti-myeloperoxidase anti-neutrophil cytoplasmic antibodies, Anti-glomerular basement membrane disease

\footnotetext{
* Correspondence: maloun@eunet.rs

${ }^{1}$ Faculty of Medicine, University of Belgrade, Belgrade, Serbia

${ }^{2}$ Institute of Mother and Child Healthcare of Serbia "Dr Vukan Čupić", 8 R

Dakica Str, 11070, Belgrade, Serbia
}

\section{Biomed Central}

(c) 2013 Bogdanović et al.; licensee BioMed Central Ltd. This is an Open Access article distributed under the terms of the Creative Commons Attribution License (http://creativecommons.org/licenses/by/2.0), which permits unrestricted use, distribution, and reproduction in any medium, provided the original work is properly cited. 


\section{Background}

The term pulmonary renal syndrome (PRS) describes the presence of diffuse alveolar hemorrhage (DAH) and glomerulonephritis as manifestations of multisystemic autoimmune disease often resulting in severe, lifethreatening condition requiring urgent, aggressive treatment $[1,2]$. It is very rare in children. The most common reported causes are systemic lupus erythematosus, antineutrophil cytoplasmic antibody (ANCA)-associated vasculitis (AAV), anti-glomerular basement membrane (GBM) disease, and Henoch-Schonlein purpura [3]. Circulating antibodies against GBM and ANCAs are both associated with crescentic glomerulonephritis (CGN) and DAH [4,5]. Their coexistence (double or dual positivity) was found in a subset of adult patients at disease presentation indicating a pathogenic link [6-13]. In children, this coexistence is extremely rare with only seven patients reported to date, five of them had an unfavorable outcome [6,14-18].

We present an exceptional case of a 10-year old girl with DAH and focal necrotizing CGN associated with circulating anti-myeloperoxidase (anti-MPO) ANCA and concomitant anti-GBM disease on renal biopsy who was successfully treated with immunosuppressive therapy. Contrary to other reported pediatric patients, renal disease was not the prominent part of clinical presentation. Pathogenesis, clinical course, treatment and outcome of disease with double positivity are discussed based on a review of reports in adults and children.

\section{Case presentation}

Previously healthy 10 -year old girl presented with intermittent fever up to $38,5^{\circ} \mathrm{C}$, fatigue, malaise, occasional headaches, legs pain and pallor. The symptoms did not prompt her or her parents to seek medical help. Two weeks later she began to cough, when laboratory investigation showed severe anemia with hemoglobin of $44 \mathrm{~g} / \mathrm{l}$ and she was admitted to the local hospital. Chest X-ray, echocardiography and ultrasound examination of abdomen were normal. After receiving transfusion of packed red blood cells (RBC) she was referred to regional hospital. During 2 weeks stay she received packed RBC transfusion on two occasions but moderate anemia (hemoglobin up to $94 \mathrm{~g} / \mathrm{l}$ ) persisted. There were no signs of hemolysis and bone marrow examination was normal. Urinalysis showed microscopic hematuria and persistent mild to moderate proteinuria (+ to ++ on dipstick) with normal renal function tests (urea $4.5 \mathrm{mmol} / \mathrm{l}$, creatinine $47 \mu \mathrm{mol} / \mathrm{l})$. A week after admission she started with dry cough again and began to expectorate blood-tinged sputum. On physical examination, inspiratory crackles over both lower lung fields were noted. Her anemia has worsened (hemoglobin $72 \mathrm{~g} / \mathrm{l}$ ), chest X-ray showed bilateral patchy pulmonary infiltrates (Figure 1a) and active pulmonary hemorrhage was suspected. This was supported by finding of patchy areas of ground-glass opacities on chest computed tomography scan (Figure 1b) suggesting diffuse alveolar hemorrhage. Therapy with prednisone, $20 \mathrm{mg} /$ day was started and she was transferred to our hospital.

On admission, she was pale with body height $(149 \mathrm{~cm})$ and body weight $(40 \mathrm{~kg})$ at 90 . Percentile. Inspiratory crackles were present bilaterally over her lower lung fields, but the rest of physical examination was unremarkable. Blood pressure (BP) was 90/60 mmHg. Chest $\mathrm{X}$-ray showed bilateral patchy pulmonary infiltrates in the middle and lower lung fields. Flexible fiber optic bronchoscopy revealed the presence of bilateral alveolar bleeding with progressively more hemorrhagic samples obtained by consecutive aliquots during bronchoalveolar lavage. The cytological analysis of these specimens showed presence of numerous hemosiderin-laden macrophages. Pulmonary function testing showed restrictive lung disease pattern (vital capacity - VC 71\% and total lung capacity - TLC 74\% predicted). Blood counts were: $\mathrm{Hb} 104 \mathrm{~g} / \mathrm{l}, \quad \mathrm{RBC} 3.8 \times 10^{12} / \mathrm{l}$, WBC $11.1 \times 10^{9} / \mathrm{l}$, Plt $411 \times 10^{9} / 1$, Rtc $3.12 \%$. Serum urea and creatinin levels were normal. Urinalysis showed microscopic hematuria (8-10 RBC/hpf) and mild proteinuria (474 $\mathrm{mg} / 24 \mathrm{~h}$ ). Presence of pulmonary and renal manifestations suggested further serological testing. Antinuclear antibodies (ANA) and anti-double stranded DNA (anti-dsDNA) antibodies were negative, and C3 and C4 components of
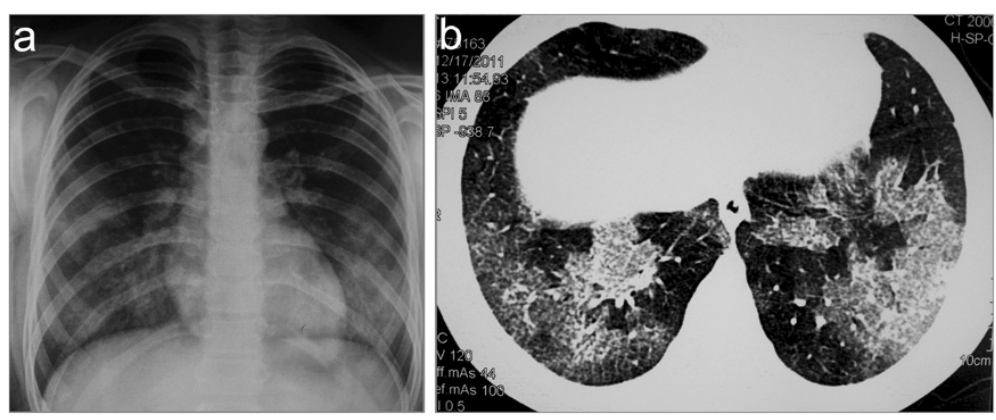

Figure 1 Chest X-ray (a) and CT scan (b) showing bilateral lung infiltrates as a result of diffuse alveolar hemorrhage. 
complement were normal. Indirect immunofluorescence (IIF) revealed perinuclear ANCA (p-ANCA) at a titer of 1:80 with antimyeloperoxidase (anti-MPO) ANCA specifity by ELISA ( $52.7 \mathrm{U} / \mathrm{ml}$, normal $<5 \mathrm{U} / \mathrm{ml})$; IIF for cytoplasmic ANCA (c-ANCA), and ELISA for antiproteinase 3 (antiPR3)-ANCA were negative, but anti-glomerular basement membrane (anti-GBM) antibodies titer (ELISA) was on borderline for positivity $(19.7 \mathrm{RU} / \mathrm{ml}$, normal $<20 \mathrm{RU} / \mathrm{ml})$. She was immediately given i.v. methylprednisolone (MP) pulses (600 mg/m $/ \mathrm{m}^{2}$ day) for 3 days, followed by prednisolone, $40 \mathrm{mg} /$ day, which resulted in cessation of hemoptysis, marked improvement of lung function (VC 90\%, TLC 91\%) and normal finding on chest X-ray within 10 days.

However, moderate anemia persisted together with moderate proteinuria $(638 \mathrm{mg} / 24 \mathrm{~h})$ and microscopic hematuria. Percutaneous renal biopsy was perfomed and tissue samples were analyzed by light microscopy (LM) and immunofluorescence (IF). LM showed cellular crescents in 4 out of 25 glomeruli and fibrinoid necrosis in 1 of 25 glomeruli (Figure 2a), with lymphomonocytic interstitial infiltration around glomeruli with crescents and perivascular infiltration of small arterioles; IF showed diffuse global linear staining of the GBM for IgG (Figure 2b) accompanied by segmental linear to granular staining for C3, suggesting anti-GBM disease $[5,19,20]$. Diagnosis of pulmonary-renal syndrome caused by anti-GBM disease and coexistent AAV was made. The treatment was then changed to a regimen consisting of prednisone (60 mg/day) for 4 weeks with subsequent taper to $30 \mathrm{mg}$ on alternate day; i.v. cyclophosphamide $(\mathrm{CY})$ pulses $\left(0.5-0.75 \mathrm{~g} / \mathrm{m}^{2}\right)$ were given monthly for total of 6 doses, followed by mycophenolate mofetil (MMF; $600 \mathrm{mg} / \mathrm{m}^{2}$ b.d.) [19,21]. Four weeks after starting this treatment her hemoglobin level $(132 \mathrm{~g} / \mathrm{L})$ and pulmonary function tests (FVC 100\%, FEV1 97\%) were normal, p-ANCA/anti-MPO ANCA returned to normal and anti-GBM antibodies were undetectable. During the 10-month follow-up she remained well, her BP and renal function test remained normal. Proteinuria remained unchanged during the first 8 months but gradually resolved thereafter, whereas two episodes of macroscopic hematuria on two occasions were occured, during unspecific febrile illnesses. At the latest follow-up visit, 10 months after starting treatment, her body weight was $44 \mathrm{~kg}$, BP was $96 / 58 \mathrm{mmHg}$, with normal findings on physical examination and normal pulmonary function tests. Her complete blood count was normal, whereas 4-6 $\mathrm{RBC} / \mathrm{hpf}$ in urine sediment were only present. Blood and urine laboratory values were as follows: urea 4.5 $\mathrm{mmol} / \mathrm{l}$, creatinine $59 \mu \mathrm{mol} / \mathrm{l}, \mathrm{p}$-ANCA negative; antiMPO ANCA $3.5 \mathrm{U} / \mathrm{ml}$; anti-GBM antibodies undetectable; proteinuria $116 \mathrm{mg} / 24 \mathrm{~h}$. Her drug therapy consisted of prednisone $15 \mathrm{mg}$ on alternate day, and MMF dose was reduced to $750 \mathrm{mg} /$ day.

\section{Discussion}

The combination of DAH and acute or rapidly progressive (crescentic) glomerulonephritis, known as Goodpasture syndrome, is used interchangeably with PRS since several different pathogenic mechanisms underlie this clinical entity $[16,22]$. PRS most commonly results from AAV or anti-GBM disease but is also described in lupus, HenochSchönlein purpura, rheumathoid arthritis and other connective tissue diseases [2].

In the anti-GBM disease the deposition of autoantibodies in the glomerular and alveolar basement membranes induces glomerulonephritis and pulmonary hemorrhage. The target antigen for the autoantibodies is the non-collagenous-1 ( $\alpha 3 \mathrm{NC1}$ ) domain of type IV collagen in the GBM, with changes in structure of the $\alpha 345$ hexamer leading to conformation change that elicits this autoimmune response [23]. In renal biopsies, linear positivity for IgG along the GBM indicates the direct pathogenetic relevance of this antibody [5].

ANCA-associated systemic vasculitides are characterized by necrotizing inflammation of the small vessels in conjunction with ANCA directed to myeloperoxidase or proteinase-3 [24]. It is shown that ANCA IgG can activate neutrophils and monocytes through Fc receptor and Fab2 binding leading to their adhesion to endothelial cells and release of cytotoxic factors which results in inflammatory injury of endothelial cells and vessel walls [5,25].

Several studies in adults reported patients with concurrence of ANCA and anti-GBM antibodies. Approximately
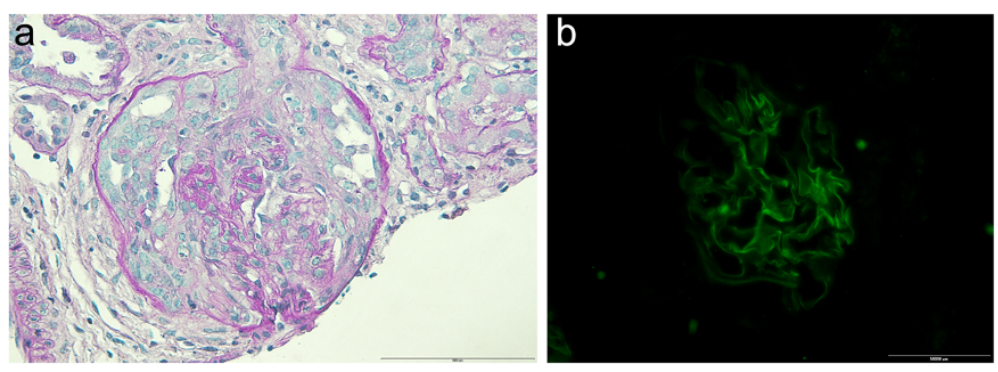

Figure 2 Light microscopy and immunofluorescent findings on renal biopsy. (a) Fibrinoid necrosis of GBM, cellular crescentic formation, and slight periglomerular limpho-monocytic infiltration (PAS, $\times 400)$; (b) Immunofluorescence: fine linear pattern along GBM stained with anti lgG antibody (×200). 
5-14\% of ANCA positive patients also had positive antiGBM antibodies [6,10,26], and $21-38 \%$ of anti-GBM antibody-positive patients also had positive ANCAs $[6-10,26,27]$, with specificity to MPO in at least two thirds of them [6-11,26,27]. The relatively high incidence of such dual positivity indicates a pathogenic link, which still has to be unraveled. Several pathogenetic hypothesis have been proposed to explain this coexistence, the most attractive one suggests an ANCA development as the initial event, with ANCA-associated mechanisms leading to the exposure of the otherwise hidden $\alpha$-3(IV)NC1 antigen and triggering anti-GBM antibody production $[11,23,28]$. This hypothesis is supported by the reports on sequential positivity of ANCA followed by anti-GBM antibodies [26,29], by the strong association between elevated ANCA titers and anti-GBM disease $[14,19]$, and by the recent findings that anti-PR3 and/or anti-MPO antibodies were always detected long before anti-GBM antibodies in anti-GBM disease patients [30]. However, the opposite sequence in double positive patients is also described [31-33].

There are reports that dual positivity in anti-GBM disease may be related to a different clinical course, at least in some patients. Older studies showed more favorable course with significant renal recovery after initiating dialysis $[6,7,34]$, but more recent reports concluded that renal prognosis is comparable to anti-GBM disease and is worse compared to patients with anti-MPO antibodies $[10,11]$. It has also been noted that incidence of pulmonary hemorrhage is lower in adult double-positive patients than in patients with ANCA-negative anti-GBM disease [6], and that dual positivity is associated with lower anti-GBM titers $[6,7,27]$. While pure anti-GBM disease is generally considered monophasic, non-relapsing illness $[5,10,12,19]$, AAV has a recurrence rate of $30-60 \%$, demanding maintenance therapy after induction of remission [35]. Dual positive patients have higher relapse rate then those with anti-GBM antibodies alone [6,9]. This suggests that an early indicator of disease relapse is needed in monitoring disease activity in double-positive patients, such as anti-hLAMP2 antibody [36,37].

Optimal therapy for double-positive patients has not been identified yet. Because of the risk of serious disease with multiple organ involvement and possible relapsing course, the addition of plasmapheresis to an immunosuppressive regimen given for AAV with continuing immunosuppression with azathioprine after 3-6 months of cyclophosphamide is recommended for these patients [38,39].

In most adult double positive patients the reported outcome was poor both in terms of the recovery of renal function and mortality $[2,6,10,11]$. The best predictor for renal survival was renal function at diagnosis: recovery of renal function in dialysis dependent patients is exceptionally rare $[7,10,40]$ as well as in those with serum creatinine exceeding $500 \mu \mathrm{mol} / \mathrm{l}$ despite undergoing treatment $[6,7,10-12,34]$. In patients who were not dialysis dependent at diagnosis, renal function depended on histological severity of disease [34]. Patients with pulmonary hemorrhage had significantly higher mortality compared to those without pulmonary hemorrhage [10]. The recurrence of disease activity with elevation of MPO-ANCA can occur many months after clinical remission, affecting either both lungs and kidneys or only one of these organs [6,12,13,31,32,41]. Most relapses responded well to methylprednisolone and/or cyclophosphamide therapy $[12,36]$.

The initial symptoms in our patient were similar to those often preceding AAV or may represent a possible infectious trigger either for one or both diseases $[19,20]$. This was followed by pulmonary hemorrhage with accompanying severe anemia. However, renal disease was relatively mild consisting of microscopic hematuria and mild to moderate proteinuria. Renal biopsy showed focal CGN with only occasional extraglomerular vasculitic changes, but without chronic glomerular or tubulointerstitial lesions. Fibrinoid necrosis with extraglomerular vasculitic changes, associated with positive pANCA/anti-MPO antibodies indicated pauci-immune ANCA disease whereas intense linear IgG staining of the GBM pointed out to an anti-GBM disease $[5,19,20]$, irrespective of normal (though high-normal) serum anti-GBM antibodies level [42]. Only active lesions were present implying the recent onset of disease. Good clinical response of pulmonary disease to corticosteroid treatment and clinically and pathologically mild to moderate renal disease led us to withhold plasmapheresis from recommended treatment regimen $[19,21]$. The subsequent course was very favorable in view of pulmonary symptoms, global renal function, rapid disappearance of anti-GBM antibodies and normalization of anti-MPO antibodies. However, the substantially unchanged proteinuria and bouts of macroscopic hematuria, that could reflect continuing vasculitic disease activity despite normal anti-MPO antibody titer [43], led us to introduce mycophenolate mofetil after stopping cyclophosphamide therapy [19], as an adjunct to the above regimen. One must assume that both the stability of pulmonary remission and lately achieved complete remission were related to an early intensive corticosteroid and $\mathrm{CY}$ therapy, followed by MMF.

The coexistance of anti-GBM antibodies and ANCAs is extremely rare in children. Searching PubMed, we were able to retrieve only seven pediatric cases reported to date, either within case series $[6,18]$ or as single case reports [14-17]. Their main features together with those in our patient are presented in Table 1. Six out of eight patients were females, aged between 4-17 years. PRS was presenting feature in all except in the youngest patient [17]. Preceding constitutional symptoms or different organ involvement were present in five of them. Crescentic glomerulonephritis with positive IgG linear 
Table 1 Main features of the reported double-positive pediatric patients

\begin{tabular}{|c|c|c|c|c|c|c|c|c|c|c|c|}
\hline \multirow{2}{*}{$\begin{array}{l}\begin{array}{l}\text { Patient } \\
\text { [ref] }\end{array} \\
1[14]\end{array}$} & \multirow{2}{*}{$\begin{array}{l}\text { Age (yr, sex) } \\
17, f\end{array}$} & \multirow{2}{*}{$\begin{array}{l}\begin{array}{l}\text { Initial } \\
\text { symptoms }\end{array} \\
\text { URTI }\end{array}$} & \multirow{2}{*}{$\begin{array}{l}\text { Hb, g/dl } \\
\sim 6.0\end{array}$} & \multicolumn{2}{|c|}{$\frac{\mathrm{S}-\mathrm{Cr}, \mathrm{mg} / \mathrm{dl}}{\text { onset } \mathrm{F} / \mathrm{U}}$} & \multirow{2}{*}{$\begin{array}{l}\text { Anti-GBM } \\
\text { Abs } \\
+\end{array}$} & \multirow{2}{*}{$\begin{array}{l}\text { ANCA } \\
\text { type }\end{array}$} & \multirow{2}{*}{$\begin{array}{l}\text { Crescents, } \\
\%\end{array}$} & \multirow{2}{*}{$\begin{array}{l}\text { Treatment } \\
\text { supportive }\end{array}$} & \multirow{2}{*}{$\begin{array}{l}F / U \\
-\end{array}$} & \multirow{2}{*}{$\begin{array}{l}\text { Outcome } \\
\begin{array}{l}\text { Death at } \\
\text { presentation }\end{array}\end{array}$} \\
\hline & & & & 12.5 & - & & & & & & \\
\hline $2[15]$ & $12, f$ & - & 7.4 & 0.5 & 0.3 & + & $\mathrm{p} / \mathrm{MPO}$ & 13 & $M P, P E, C Y$ & few weeks & Normal GFR \\
\hline $3[16]$ & $12, \mathrm{~m}$ & $\begin{array}{l}\text { fever,rash, } \\
\text { arthritis }\end{array}$ & 10.6 & 7.4 & 2.1 & + & $\mathrm{p} / \mathrm{MPO}$ & $>60$ & $\begin{array}{l}\text { PE, MP, CY Pdn, } \\
\text { MMF }\end{array}$ & $18 \mathrm{mos}$ & GFR $58.5 \mathrm{ml} / \mathrm{min}$ \\
\hline $4[17]$ & $4, f$ & epistaxis & n.a. & 2.7 & 0.8 & + & $\mathrm{p} / \mathrm{MPO}$ & 62 & $P E, M P, P d n, C Y$ & 9 mos & Normal GFR \\
\hline $5[18]$ & $8, f$ & sore throat & 2.8 & 7.7 & - & - & $\mathrm{p} / \mathrm{MPO}$ & 83 & supportive & - & $\begin{array}{l}\text { Death at } \\
\text { presentation }\end{array}$ \\
\hline $6[6]$ & $13, \mathrm{~m}$ & rash, sinusitis & n.a. & $D$ & D & + & C/PR3 & + & $P E, P d n, C Y$ & n.a. & ESRD \\
\hline $7[6]$ & $17, f$ & & n.a. & D & D & + & $\mathrm{p} / \mathrm{MPO}$ & 20 & $P E, C Y, P d n$, Aza & n.a. & ESRD \\
\hline $\begin{array}{l}8 \text { [this } \\
\text { report] }\end{array}$ & $10, f$ & $\begin{array}{l}\text { fever, malaise, } \\
\text { legs pain }\end{array}$ & 4.4 & 0.53 & 0.66 & \pm & $\mathrm{p} / \mathrm{MPO}$ & 16 & $\begin{array}{l}\text { MP, CY, Pdn, } \\
\text { MMF }\end{array}$ & 10 mos & Normal GFR \\
\hline
\end{tabular}

URTI, upper respiratory tract infection; F/U, follow-up; $A b s$, antibodies; $p$, perinuclear; $M P O$, myeloperoxidase; $P R 3$, proteinase-3; $M P$, methyl-prednisolone; $P E$, plasma exchange; $C Y$, cyclophosphamide; GFR, glomerular filtration rate; $P d n$, prednisone; $M M F$, mycophenolate mofetil; $A z a$, azathioprine; $E S R D$, end-stage renal disease; $D$, dialysis; $S$-Cr, serum creatinine concentration; GBM, glomerular basement membrane;

$A N C A$, anti-neutrophil cytoplasmic antibodies; n.a., not available; +, positive/present; -, negative/absent. 
straining along the GBM was found in all eight patients, with percentage of crescents ranging from 13\% to $90 \%$ in kidney biopsy samples. In one patient, an 8-year old girl [18], circulating anti-GBM antibodies were not detected whereas they were at the upper limit of normal in our patient, despite prominent linear IgG staining in the GBM in both of them. It has been estimated that $2-3 \%$ of patients with anti-GBM disease may have circulating antibody levels that are undetectable by standard assays, but can be detected by a more sensitive method [42]. In these cases, diagnosis of anti-GBM disease may be based on intense linear staining of the GBM after exclusion of other conditions, also presenting with linear staining, but extremely rare in children $[5,42]$. Only one patient had c-ANCA with anti-PR-3 specifity, whereas $\mathrm{p}$-ANCA/anti-MPO antibodies were found in other seven patients. Although MPO specifity is the predominant pattern found in dual positivity, this phenomenon can be seen either with MPO or PR3 $[6,32]$. All survived patients were treated by combination of immunosuppressive drugs and all except our patient received plasmapheresis.

In both $\mathrm{AAV}$ and anti-GBM disease the addition of plasmapheresis to initial immunosuppressive therapy is indicated in patients with severe renal dysfunction or with DAH $[19,20,38,39]$. The recommendation for plasmapheresis in double positive patients is based on the rationale for the treatment of anti-GBM disease [38,39]. The observation of worse outcome in patients with double positivity compared to those with either AAV or anti-GBM disease alone [11] may add further support to this strategy. However, it is unknown whether patients with milder alveolar hemorrhage require plasmapheresis [38]. According to these criteria, plasmapheresis was indicated in our patient. However, quick favorable response to intensive immunomodulating therapy as well as the absence of severe renal dysfunction, led us to withhold plasmapheresis from the standard treatment approach. In a few anti-GBM disease patients having DAH and normal renal function, good outcome was seen without adding plasmapheresis to immunosuppression [44]. However, we could not find a similar case among AAV patients or double positive patients reported to date. The unfavorable outcome in children with double positivity and DAH, having either low or high percentage of glomeruli with crescents $[6,14,18]$, strongly remind of the serious nature of the disease for which we do not still have robust indicator to assist with optimal personalized therapy.

The outcome of reported pediatric cases is not different from that in adults: two patients died at presentation from massive pulmonary hemorrhage $[14,18]$; two patients, both dialysis dependent at presentation, remained in end-stage renal disease (ESRD) [6]; one patient, whose treatment was delayed 5 months after clinical onset, improved renal function [16]; three patients, including ours, had normal renal function several weeks to 10 months after onset of disease $[15,17]$. Our patient and a 12-year old girl reported by Paueksakon et al. [15] had normal renal function at onset with cellular crescents in only $16 \%$ or $13 \%$ of glomeruli, respectively. These two patients may resemble to a small subgroup of younger adult patients with anti-GBM disease presenting with milder kidney involvement and an excellent prognosis despite severe pulmonary hemorrhage [44]. The third patient, 4-year-old girl, who is the youngest patient, had advanced disease, as shown by $62 \%$ of glomeruli with crescents and $33 \%$ globally sclerosed, responded well to treatment [17], similarly to very rare adult patients $[7,10,40]$. On the other hand, a 17-year old girl with only $20 \%$ of crescents on biopsy was dialysis dependent at presentation and remained in ESRD despite plasmapheresis and aggressive immunosuppression. No other details are given except that she had significant glomerular sclerosis [6]. One patient had relapse with pulmonary hemorrhage six months after onset [6].

\section{Conclusion}

The pulmonary renal syndrome is very rare in children but represents a serious medical emergency with significant morbidity and mortality. An early diagnosis is crucial and laboratory investigation should be directed toward testing for presence of different antibodies. The coexistence of anti-GBM antibodies and ANCAs is exceptionally rare in children. Rapid institution of plasmapheresis and aggressive immunosuppressive therapy can induce remission and preserve renal function in dual positive patients with PRS. Prolonged therapy, long-term follow-up and close monitoring are necessary as relapses may occur. Renal prognosis depends on the extent of kidney injury at diagnosis and appropriate treatment.

\section{Consent}

Written informed consent was obtained from the child's father for publication of case report and any accompanying images.

\section{Abbreviations}

AAV: ANCA-associated vasculitis; ANA: Antinuclear antibodies; ANCA: Antineutrophil cytoplasmic antibodies; BP: Blood pressure; CGN: Crescentic glomerulonephritis; CT: Computed tomography; CY: Cyclophosphamide; DAH: Diffuse alveolar hemorrhage; ds-DNA: Double stranded deoxyribonucleic acid; ELISA: Enzyme linked immunoassay; ESRD: End stage renal disease; GBM: Glomerular basement membrane;

IF: Immunofluorescence; IIF: Indirect immunofluorescence; LM: Light microscopy; LM: Light microscopy; MMF: Mycophenolate mofetil; MPO: Myeloperoxidase; PR3: Proteinase-3; PRS: Pulmonary renal syndrome; RBC: Red blood cells; TLC: Total lung capacity; VC: Vital capacity.

\section{Competing interests}

The authors declare that they have no competing interests. 


\section{Authors' contributions}

$R B, P M, N S, N S$, and MR were the physicians who treated the patient in this report. JM-L performed the pathology studies. The manuscript was prepared by RB. All authors participated in discussions about the manuscript and approved the final version

\section{Acknowledgments}

This work was presented at the 45th ESPN Annual Meeting, September 6-8, 2012, Krakow, Poland (Pediatr Nephrol 2012; 27:1696A). The work was supported by the grants from the Ministry of Education and Science, Republic of Serbia, Projects No Ol175079 (RB) and Ol175047 (JM-L, RB). Mrs B. Krsmanović helped in preparing the manuscript. PharmaSwiss d.o.o. Belgrade and MSD d.o.o. Belgrade supported publication.

Received: 27 November 2012 Accepted: 15 March 2013

Published: 22 March 2013

\section{References}

1. Gallagher H, Kwan JTC, Jayne DRW: Pulmonary renal syndrome: A 4-year, single-center experience. Am J Kidney Dis 2002, 39:42-47.

2. Lee RW, D'Cruz DP: Pulmonary renal vasculitis syndromes. Autoimmun Rev 2010, 9:657-660

3. Von Vigier RO, Trummler SA, Laux-End R, Sauvain MJ, Truttmann AC, Bianchetti MG: Pulmonary renal syndrome in childhood: a report of twenty-one cases and a review of the literature. Pediatr Pulmonol 2000, 29:382-388

4. Jennette JC, Falk RJ: Small-vessel vasculitis. N Engl J Med 1997, 337:1512-1523.

5. Kluth DC, Rees AJ: Anti-glomerular basement membrane disease. J Am Soc Nephrol 1999, 10:2446-2453.

6. Jayne DRW, Marshall PD, Jones SJ, Lockwood CM: Autoantibodies to GBM and neutrophil cytoplasm in rapidly progressive glomerulonephritis. Kidney Int 1990, 37:965-970.

7. Bosch X, Mirapeix E, Font J, Cervera R, Ingelmo M, Khamashta MA, Revert L, Hughes GR, Urbano-Marquez A: Anti-myeloperoxidase autoantibodies in patients with necrotizing glomerular and alveolar capillaritis. Am J Kidney Dis 1992, 20:231-239.

8. Weber MFA, Nadrossy K, Pullig O, Koderisch J, Netzer K: Antineutrophilcytoplasmic antibodies and antiglomerular basement membrane antibodies in Goodpasture's syndrome and in Wegener's granulomatosis. J Am Soc Nephrol 1992, 2:1227-1234.

9. Short AK, Esnault VL, Lockwood CM: Anti-neutrophil cytoplasm antibodies and anti-glomerular basement membrane antibodies: two coexisting distinct autoreactivities detectable in patients with rapidly progressive glomerulonephritis. Am J Kidney Dis 1995, 26:439-445.

10. Levy JB, Hammad T, Coulthart A, Dougan T, Pusey CD: Clinical features and outcome of patients with both ANCA and anti-GBM antibodies. Kidney Int 2004, 66:2535-2540.

11. Rutgers A, Slot M, Passen PV, Vriesman PVB, Heeninga P, Tervaert JWC: Coexistence of anti-glomerular basement membrane antibodies and myeloperoxidase-ANCAs in crescentis gomerulonephritis. Am J Kidney Dis 2005, 46:253-262.

12. Lindič J, Vizjak A, Ferluga D, Kovač D, Aleš A, Kveder R, Ponikvar R, Bren A: Clinical outcome of patients with coexistent antineutrophil cytoplasmic antibodies and antibodies against glomerular basement membrane. Ther Apher Dial 2009, 13:278-281.

13. Zoysa J, Taylor D, Thein H, Yehia M: Incidence and features of dual antiGBM-positive and ANCA-positive patients. Nephrology 2011, 16:725-729.

14. Fanburg BL, Niles JL, Mark EJ: Case 52-1993: A 17-year-old girl with massive hemoptysis and acute oliguric renal failure. N Engl J Med 1993, 329:2019-2026.

15. Paueksakon P, Hynley TE, Lee SM, Fogo AB: A 12-year-old girl with pulmonary hemorrhage, skin lesions, and hematuria. Am J Kidney Dis 1999, 33:404-409.

16. Hijosa MM, Espinosa RL, Fernandez C, Picazo Garcia ML, Pascual Salcedo D, Navarro Torres M: Anti-GBM and anti-MPO antibodies coexist in a case of pulmonary renal syndrome. Pediatr Nephrol 2005, 20:807-810.

17. Naidoo S, Waller S: Anti-GBM antibodies co-exist with MPO-ANCA in a 4-year-old girl with acute renal failure. Pediatr Nephrol 2009, 24:215-216.
18. Williamson SR, Phillips CL, Andreoli SP, Nailescu C: A 25-year experience with pediatric anti-glomerular basement membrane disease. Pediatr Nephrol 2011, 26:85-91.

19. Lionaki S, Jennette JC, Falk RJ: Anti-neutrophil cytoplasmic (ANCA) and anti-glomerular basement membrane (GBM) autoantibodies in necrotizing and crescentic glomerulonephritis. Semin Immunopathol 2007, 29:459-474.

20. Kambham N: Crescentic glomerulonephritis: an update on pauci-immune and anti-GBM diseases. Adv Anat Pathol 2012, 19:111-124.

21. Rees L, Webb NJA, Brogan PA: Vasculitis. In Paediatric Nephrology. Edited by Rees L, Webb NJA, Brogan PA. Oxford: OUP; 2007:297-316.

22. Valentini RP: Pediatric anti-GBM disease (Good pasture Syndrome). http:// emedicine.medscape.com/article/1001872-overview.

23. Pedchenko V, Vanacore R, Hudson B: Goodpasture's disease: molecular architecture of the autoantigen provides clues to etiology and pathogenesis. Curr Opin Nephrol Hypertens 2011, 20:290-296.

24. Kallenberg CG: Pathogenesis of ANCA-associated vasculitides. Ann Rheum Dis 2011, 70:159-163.

25. Jennette JC, Falk RJ, Gasim AH: Pathogenesis of antineutrophil cytoplasmic autoantibody vasculitis. Curr Opin Nephrol Hypertens 2011, 20:263-270.

26. Hellmark T, Niles JL, Collins B, Mccluskey RT, Brunmark C: Comparison of anti-GBM antibodies in sera with or without ANCA. J Am Soc Nephrol 1997, 8:376-385.

27. Yang $R$, Hellmark $T$, Zhao J, Cui Z, Segelmark M, Zhao M, Wang H: Antigen and epitope specificity of anti-glomerular basement membrane antibodies in patients with Goodpasture disease with or without antineutrophil cytoplasmic antibodies. J Am Soc Nephrol 2007, 18:1338-1343.

28. Hudson BG, Tryggvason K, Sudaramoorthy M, Neilson EG: Alport's syndrome, Goodpasture's syndrome, and type IV colagen. N Engl J Med 2003, 348:2543-2556.

29. Serratrice J, Chiche L, Dussol B, Granel B, Daniel L, Jego-Desplat S, Disdier P, Swiader L, Berland $Y$, Weiller PJ: Sequential development of perinuclear ANCA-associated vasculitis and anti-glomerular basement membrane glomerulonephritis. Am J Kidney Dis 2004, 43:e26-e30.

30. Olson SW, Arbogast CB, Baker TP, Owhalimpur D, Oliver DK, Abbott KC, Yuan CM: Asymptomatic autoantibodies associate with future antiglomerular basement membrane disease. J Am Soc Nephrol 2011, 22:1946-1952.

31. Peces R, Rodrigues M, Pobes A, Seco M: Sequential development of pulmonary hemorrhage with MPO-ANCA complicating anti-glomerular basment membrane antibody-mediated glomerulonephritis. Am J Kidney Dis 2000, 35:954-957.

32. Desai A, Goldschmidt RA, Kim GC: Sequential development of pulmonary renal syndrome asociated with c-ANCA 3 years after development of anti-GBM glomerulonephritis. Nephrol Dial Transplant 2007, 22:926-929.

33. Vanhille PH, Noel LH, Reumaux D, Fleury D, Lemaitre V, Gobert P: Late emergence of systemic vasculitis with anti-neutrophil cytoplasmic antibodies in a dialyzed patient with anti-glomerular basement glomerulonephritis. Clin Nephrol 1990, 33:257-258.

34. Segelmark M, Hellmark T, Wieslander J: The prognostic significance in Goodpasture's disease of specificity, titre and affinity of anti-glomerular -basement-membrane antibodies. Nephrol Clin Pract 2003, 94:c59-c68.

35. Mukhtvar C, Guillevin J, Cid MC, Dasgupta B, De Groot K, Gross W, Hauser T, Hellmich B, Jayne D, Kallenberg CG, Merkel PA, Raspe H, Salvarani C, Scot DG, Stegman C, Watts R, Westman K, Witter J, Yazici H, Luqmani R: European vasculitis study group: EULAR recommendations for the management of primary small and medium vessel vasculitis. Ann Rheum Dis 2009, 68:310-317.

36. Etter C, Gaspert A, Regenass S, Wuthrich R, Kistler T, Kain R, Cohen C: AntihLAMP2-antibodies and dual positivity for anti-GBM and MPO-ANCA in a patient with relapsing pulmonary-renal syndrome. BMC Nephrol 2011, 12:1471-2369.

37. Kain R, Tadema H, McKinney EF, Benharkou A, Brandes R, Peschel A, Hubert V, Feenstra T, Sengolge G, Stegeman C, Heeringa P, Lyons PA, Smith KG, Kallenberg C, Rees AJ: High prevalence of autoantibodies to hLAMP-2 in anti-neutrophil cytoplasmic antibody-associated vasculitis. J Am Soc Nephrol 2012, 23:556-566.

38. KDIGO Clinical Practice Guidelines for Glomerulonephritis: Pauci-immune focal and segmental necrotizing glomerulonephritis. Kidney Int Suppl 2012, 2:233-239. 
39. Jennette JC, Falk R: Renal and systemic vasculitis. In Comprehensive Clinical Nephrology. 4th edition. Edited by Floege J, Jonson RJ, Feehally J. St Louis: Elsevier; 2010:292-307.

40. Mandai S, Nagahama K, Tsuura Y, Hirai T, Yoshioka W, Takahashi D, Aki S, Aoyagi $\mathrm{M}$, Tanaka H, Tamura T: Recovery of renal function in a dialysis-dependent patient with microscopic polyangiitis and both myeloperoxidase antineutrophil cytoplasmic antibodies and anti-glomerular basement membrane antibodies. Intern Med 2011, 50:1599-1603.

41. Verburgh CA, Bruijn JA, Daha MR, vas Es LA: Sequential development of anti-GBM nephritis and ANCA-associated pauci-immune glomerulonephritis. Am J Kidney Dis 1999, 34:344-348.

42. Salama AD, Dougan T, Levy JB: Goodpasture's disease in the absence of circulating anti-glomerular basement membrane antibodies as detected by standard techniques. Am J Kidney Dis 2002, 39:1162-1167.

43. Savige J, Davies D, Falk RJ, Jennette JC, Wiik A: Antineutrophil cytoplasmic antibodies and associated diseases: a review of the clinical and laboratory features. Kidney Int 2000, 57:846-862.

44. Cui Z, M-h Z, Wang H-y: Antiglomerular basement membrane disease with normal renal function. Kidney Int 2007, 12:1403-1408.

doi:10.1186/1471-2369-14-66

Cite this article as: Bogdanović et al:: Pulmonary renal syndrome in a child with coexistence of anti-neutrophil cytoplasmic antibodies and anti-glomerular basement membrane disease: case report and literature review. BMC Nephrology 2013 14:66.

\section{Submit your next manuscript to BioMed Central and take full advantage of:}

- Convenient online submission

- Thorough peer review

- No space constraints or color figure charges

- Immediate publication on acceptance

- Inclusion in PubMed, CAS, Scopus and Google Scholar

- Research which is freely available for redistribution 